in the velocity of the particles alter the distance between the bright patches in Fig. 2, giving the effect of changes of luminosity running round a circle, a well-known auroral phenomenon. Other phenomena analogous to the "dancing " of auroral rays are easily produced by advancing or withdrawing a bar magnet. M. Villard seems to regard magnetic disturbances rather as agents causing auroral phenomena than the converse, but his theory seems still in a somewhat uncrystallised state. Those actually familiar with auroral phenomena will think of a number of points requiring explanation to which $M$. Villard does not refer; but his researches, like those of Prof. Birkeland, are at all events highly interesting and suggestive.

C. Chree.

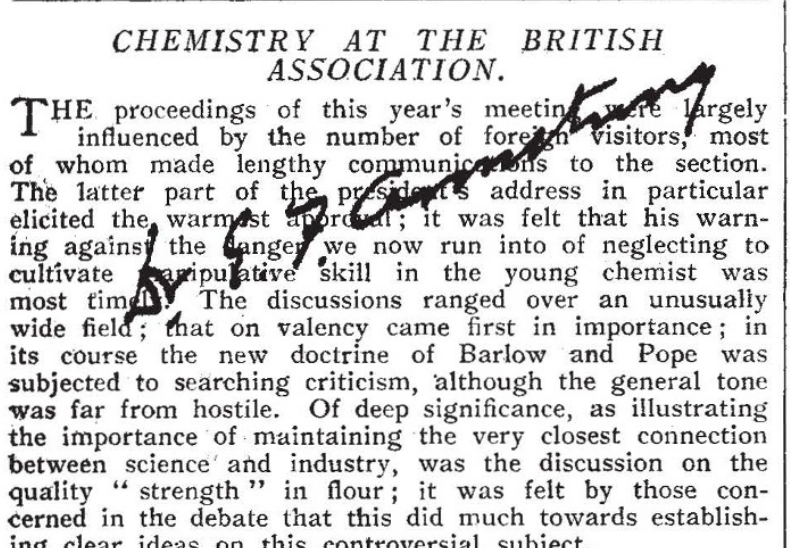
ing clear ideas on this controversial subject.

Prof. Pope opened the discussion on valency with an account of the theory put forward by Mr. W. M. Barlow and himself. Combining chemical with crystallographic data, it is possible to show that the fundamental valency of an element represents, very approximately, the number of units of volume contained in the polyhedral cell which constitutes the domain of its atom in any molecular assemblage. Valency, from this point of view, is primarily a simple volume relation. If the atoms are regarded as centres of attraction and repulsion, a crystalline structure may be considered to be an equilibrium arrangement of such centres. If each atom be allotted its own polyhedral cell or sphere of influence, the simplest assumption that can be made as to the shape of these spaces is that they depart as little as possible from sphericity. The polyhedral cells must fill space without leaving interstices, and the centres of the identical polyhedral cells will be those of the centres of a closest packed assemblage of equal spheres. There ars two varieties of homogeneous arrangement of equal spheres in closest packing, distinguished as the cubical and the hexagonal closest packed arrangements.

A crystalline element, in which no molecular aggregation of the single atoms occurs, should thus exhibit holohedral cubic or hexagonal symmetry. Of the forty known crystalline forms of the elements, only six are neither cubic nor hexagonal; in the rest the axial ratios all approximate to the theoretical values calculated on the above hypothesis. The binary compounds can be constructed from spheres of two kinds, but of approximately equal size, present in equal numbers.

This hypothesis has been worked out in detail in the case of the alkati haloid salts and of silver iodide. The assemblages thus constructed present geometrical properties which are extirely in harmony with corresponding physical properties of the crystalline material. The cleavage, twinning, and gliding of the cubic alkali haloid salts and the dimorphism of silver iodide are precisely paralleled by corresponding properties of the assemblages suggested as representing the crystalline structures of these salts.

Each crystalline substance is to be regarded as a closepacked homogeneous assemblage of the spheres of atomic influence.

Prof. Sollas criticised the form of close packing put No. 1975 , VOL. 76$]$ forward by Messrs. Barlow and Pope, and objected to the structure suggested for silver iodide on the grounds that it did not explain the sudden contraction in volume of this substance when heated to a certain temperature. $\mathrm{He}$ described and showed models to. illustrate an alternative system. Prof. Miers agreed that the fact that more than 80 per cent. of the elements and binary compounds crystallise in the cubic system was a strong argument in favour of closest packing, yet this principle must be tested by all the physical properties as well as the geometric form of the crystals. Dr. Tutton also criticised the idea of closest packing; he suggested that the topic axial ratios should be taken as an index and measure of the relative closeness of the packing.

Prof. Abegg pointed out that, according to van der Waals, in the liquid state three-eighths of the volume are occupied by matter and five-eighths are free space, and that as substances changing from liquid to solid do not vary essentially in volume, this would seem opposed to the idea of close packing. In answer to the above, Mr. Barlow explained that the spheres were only in reality centres of influence and attraction, and thus there was no real distinction between loose and tight packing. Prof. Tilden remarked that the authors in their explanation of what happens when a change of valency occurs did not appear to recognise that there are two kinds of valency, the one corresponding to the electric charges and the other an extra valency developed under special conditions.

Prof. Larmor thought that the views of the authors seemed to carry weight in their application to the forms of crystals. The approximation that is exhibited by actual crystalline forms to those calculated for dyad molecules consisting each of two equal spheres or nearly spherical domains of influence seemed noteworthy; it gained even more weight when it was remembered that considerable difference in size of the spheres would produce but little difference in the ratios, so that the restriction to equality of the domain of influence could be largely dispensed with and yet the results remain substantially as they are. $\mathrm{He}$ hazarded the suggestion that the direct operations of the chemist can grasp only those molecules which have pronounced architectural features, but that there may be whole regions of incipient combinations which do not submit to architectural modification, though they may be recognisable indirectly, as by the spectroscope.

The electrochemical aspect of valency was to associate it with the number of loose and displaceable electrons in the atom. The essential physical features of a metallic atom being generally that a certain number of its negative electrons are thus relatively free, we may imagine that when it is in combination to form a molecule of a salt these electrons are attracted across into the domain of the radicle thus united with it, and when accidental separation occurs in the appropriate way they may remain there. But while something like this is a fact, the mechanism remains largely a mystery, as it has been ever since valency was first connected in this way with electric. displacement by Faraday eighty years ago.

Prof. Werner (Zurich) and Prof. Abegg (Breslaul) gave descriptions of their views on the broader questions of valency. Prof. Kauffmann (Stuttgart) spoke on the divisibility of valency, and dealt briefly with his own investigations on the colour and fluorescence of organic compounds in connection with structure.

The second morning was entirely given up to a joint discussion with Section $G$ on explosion temperatures, in which Profs. Boudouard, Haber, Smithells, and H. B. Dixon spoke on the chemical side. In the afternoon Prof. Dixon described his observations on the ignition point of various gases and mixtures. In the discussion which followed Mr. Dugald Clerk dwelt on the trouble arising from pre-ignition in large gas engines, and showed that it was important to be able to predict the ignition temperature from the nature of a mixture of gases, and so to allow proper compression space in designing the engine.

Dr. H. O. Jones gave a concise account of work carried out with Sir James Dewar on iron carbonyls. The pentacarbonyl is a yellow liquid, which resembles nickel tetracarbonyl in its properties, but is more stable towards 
chemical reagents. When decomposed it always gives rise to ferrous salts. On exposure to light it yields carbon monoxide and an orange crystalline solid-diferrononacarbonyl, $\mathrm{Fe}_{2}(\mathrm{CO})_{9}$. This, when heated alone, gives a dark green liquid consisting chiefly of iron pentacarbonyl, but when hydrocarbons or ether are present in excess and the temperature is maintained below $100^{\circ} \mathrm{C}$., an intensely green-coloured solution is obtained, which deposits dark green lustrous crystals of iron tetracarbonyl, $\mathrm{Fe}(\mathrm{CO})_{4}$. This is stable towards reagents, and its dark green solution in organic solvents exhibits a characteristic absorption band in the yellow.

Dr. K. S. Caldwell described his investigations on the conductivity of electrolytes in pyridine carried out in Leipzig in Prof. Hantzsch's laboratory. With the exception of the pyridonium halides, the true acids, compared among themselves, follow approximately the same order in pyridine as in water, and the same applies to the pseudo-acids, which, however, yield much better conducting solutions than do true acids having the same or even greater affinity constants. He further dealt with the influence of temperature on the conductivity of electrolytes in pyridine solution. The temperature of maximum conductivity is well marked, but it is not higher the greater the conductivity as in the case of solutions in liquid sulphur dioxide. Pyridonium salts in pyridine show an abnormally high conductivity.

On Monday Dr. Alex. McKenzie presented a valuable report on the applications of Grignard's interaction. Since the discovery in 1900 that a vigorous action ensues when magnesium powder is added to a mixture of methyl iodide and anhydrous ether, and that this product is extremely active, the Grignard method has been applied with important results in almost every branch of organic chemistry, and the progress made with its help in so short a time as six years is little short of amazing.

By means of it, secondary alcohols are obtained from aldehydes, tertiary alcohols from ketones, acid chlorides or acid anhydrides. Unsaturated hydrocarbons are also obtained from aldehydes, ketones, \&c., under suitable conditions. It is also applicable to the preparation of carboxylic, sulphinic and other sulphur acids, of ketones, aldehydes, ethers and esters, and also of alkyl and aryi metallic compounds. Dr. McKenzie dealt at length with the preparation of the agent, and this part of the report should prove of the utmost value to future workers in this field.

Prof. Tschitschibabin, of Moscow, read a valuable paper on triphenylmethyl, in which he discussed the formula of this remarkable substance. Dr. Chattaway described his copper mirrors discovered in the course of an investigation on the oxidation of aromatic hydrazines. When solutions of cupric salts are reduced by these compounds the metal is deposited on the glass in the form of a brilliant coherent film. A number of such mirrors were exhibited; they showed the fustrous red colour of burnished copper, and were perfect in reflecting surface and uniformity; Dr. Boudouard contributed an account in French of the suboxides of carbon.

Dr. Jaeger, of Amsterdam, described the colour changes which occur on melting cholesterol esters, and dealt with the theory of these from the point of view of the phase rule. The colours are due to the formation of doubly refracting layers of liquid crystals and occur at, or a few degrees below, the transition temperatures whilst the two liquid layers are separating from each other. The author gave a striking demonstration of these liquid crystals.

Prof. Phillips Bedson described and exhibited an apparatus for studying the inflammability of mixtures of coal dust and air, consisting of an arrangement whereby the dust was projected. by a blast of air through a gap between two platinum wires, and there subjected to a series of electric sparks. A number of interesting experiments were shown with this apparatus; in one instance the flame produced by the ignition of dust at one point was made to ignite a cloud of dust at a point 2 feet or 3 feet distant from the point of inflammation.

Another experimental paper was contributed by $\mathrm{Mr}$. Pratt, who described some properties of metallic calcium, which seems to have industrial possibilities as a reducing agent. In discussing the paper, Dr. F. M. Perkin No. 1975 , voL. 76$]$ mentioned his own experiments with turnings of metallic calcium, which has a more powerful reducing action on oxides than aluminium.

The reports of the research committees were as usual of considerable interest. Dr. Lowry, in the report on dynamic isomerism, brought forward very definite evidence in favour of his view that the isomeric change, which usually takes place when nitrocamphor is dissolved in chloroform or benzene, does not occur spontaneously, but is conditioned by the presence of minute traces of alkaline impurities. So sensitive is this change to piperidine that it is complete in ten hours under the influence of so small a quantity as $\mathrm{N} / \mathrm{r}, 000,000$.

Dr. Orton's report on the transformation of aromatic nitroamines also laid stress on the important part played by the transforming agent in intramolecular changes which, accepting Armstrong's view, is regarded as forming an additive compound with the nitroamine. Dr. Crossley's report on hydroaromatic substances, besides giving an account of the tesearches made by the committee, included the usual valuable summary of recent work done in this field.

The discussion on the chemistry of flour was opened by Mr. A. E. Humphries with a short paper entitled "The Causes of the Quality Strength in Wheaten Flour." To make bread of the quality requed in this country today what are known as strong flours are required, that is, flours which have the capacity of making big, shapely loaves. Most English-grown wheats are deficient in this quality of strength, and give what are known as weak flours. When attempts are made to grow a foreign strong wheat in this country, the yield of grain and straw is, as a rule, too low to make the culture pay. It has been the object of the Home-grown. Wheat Committee of the National Association of British and Irish Millers to produce such wheats in England as shall combine strength with maximum crops of grain and straw. In addition to botanical and field work, this problem has demanded the solution of the question, What is the ultimate cause of strength and the nature and source of those constituents which confer on some varieties of wheat the inherent quality of strength and the power of transmitting it?

It has been proved that though climate and soil influence quality, they are not the determining factors in the production of strength, for though the strongest wheats are ordinarily produced in districts where the winters are cold, the summers hot, and the summer rainfall high, certain varieties possess and retain the inherent quality of strength when grown in England. Manuring or early cutting at harvest time has no beneficial effect on quality. Quick growth or rapid maturation is not correlated with strength, nor does the percentage of natural moisture in wellharvested wheat indicate it; indeed, in certain cases the addition of water to wheat materially increases its effective baking strength.

The term "strength" has been loosely applied to cover several characteristics. In the view of the committee it should not be measured by the quantity of water required to make doughs of a standard consistency, nor by the quantity of bread produced per sack of flour used, nor by the way a flour behaves in the dough, but by its capacity for making big, shapely, and therefore well-aërated loaves. This definition covers two characteristics; one, a flour's capacity for making gas in yeast fermentation; the other, its capacity when made into dough for retaining the gas so generated.

The gas-making power will depend largely on the percentage of natural sugar any given wheat contains and its diastatic capacity. These characteristics vary substantially in different wheats. The baker can, and does, influence the quantity of gas generated in baking. The retention of gas when made involves complex problems.

Mr. A. D. Hall pointed out that the old idea that the wheat plant takes definite materials out of the soil to give it strength is incorrect, and emphasised the view that each type of wheat elaborates a mixture of starch, proteins, \&c., of definite proportions right from the very beginning, so that the plant as an individual affords a characteristic product. Strength on this assumption is a congenital factor, and probably a "character" in the Mendelian sense. 
Prof. T. B. Wood described in detail experimental investigations from which he concludes that two factors are involved in the term strength, that of size, which is a function of the gas evolved by the flour due to its diastatic capacity, and that of shape, which is a function of the proportion of acid and salts present in the flour. $\mathrm{Mr}$. Julian Baker mentioned some determinations of the diastatic power of flours from which he infers that diastase is always present in excess, so that the determination of diastatic power will not be of much value in judging a flour. Dr. E. F. Armstrong alluded to the importance of the gas formed during the early stages of fermentation in distending and affecting the gluten, and pointed out, as also did Mr. Baker, that the enzymes of flour other than diastase should receive the closest attention.

\section{GEOLOGY AT THE BRITISH}

\section{ASSOCIATION}

THE papers on local geology which followed the presi1 dent's address yere of more than ordinary interest. Mr. Fox Strangw ds dealt wist the district round Leicester a a whole, dwellin specially on those points which are oscurg and reatre further elucidation. Prof. Watts gav an ackoy of his researches in the rocks of the Charnfood Forest. Dr. F. Bennett and Dr. B. Stacey, in describing the felsitic agglomerates occurring at Bardor Hill and in other parts of Charnwood, gave a new reding of some of the features described by Prof. Watts. These questions raised an interesting discussion, which was carried on, not only in the sectional meetings, but also in the field, when the localities were visited in the course of the admirable series of afternoon excursions which had been arranged by the local secretary of the section.

A full day was given to papers dealing with the Triassic rocks. Mr. H. T. Ferrar led off with a description of the features and activities of the desert regions of eastern and western Egypt, and he dealt more particularly with those which have a bearing on the origin of the British Trias. The Libyan Desert presents broad, featureless plains, with no very definite drainage system, and the veneer of waste is protected from removal by wind by layers of pebbles. The Etbai, on the other hand, displays bare hillsides free from débris, aggrading wadis, no sand dunes, and an integrated drainage system.

The origin of the Trias about Leicester was very ably discussed by $\mathrm{Mr}$. T. O. Bosworth. He showed that the Charnian rocks beneath the Keuper were fresh right up to the surface, and when the marl had been denuded, the igneous rocks of Mount Sorrel, Croft, Scapcote, Groby, \&c., were smoothed, fretted, and carved by wind action. The beds themselves dip in the direction of the slope of the underlying rocks, and catenary bedding is seen at Croft and Groby. At the base of the marls, too, there are breccias with chemically unaltered stones, and these he considered to be desert screes. Such evidence of subaqueous deposition as there is points to the existence of occasional streams and salt pools rather than the deep waters of one great Keuper lake.

Messrs. Keay and Gimson discussed the relation of the Keuper marls to the pre-Cambrian rocks at Bardon Hill. They showed that the Keuper fills in joints of the preCambrian rocks to a height of 880 feet, which is the greatest altitude yet reached in Britain for any rocks of the Triassic system.

Dr. Cullis, in dealing with the mineralogical constitution of the Keuper marls in the west of England, announced the discovery of minute crystals of dolomite, which he contended were precipitated from the waters of an inland sea. In the discussion which followed, $\mathrm{Mr}$. Lomas showed that dolomite was absent from the Keuper marls of the north of England, and their occurrence in the sands now being laid down by the River Mersey showed that other modes of origin are possible. The exact manner in which limestones become dolomitised and crystals of dolomite are produced in sands is still a matter of great uncertainty, and no satisfactory explanation has yet been offered.

Messrs. Bolton and Waterfall communicated a Daper on the occurrence of boulders of strontia in the Upper
Triassic marls of Abbots Leigh, near Bristol. This remarkable deposit contains boulders of all sizes from a pea to 100 tons in weight; the yield is about 2000 tons per acre, and it has become the principal world's supply of this mineral.

The fifth report of the committee appointed to investigate the fauna and flora of the Trias was presented by the secretary. To this report Dr. A. Smith Woodward contributed an important paper on a mandible of Labyrinthodon leptognathus, Owen, recently obtained from the Keuper sandstone of Cubbington Heath, near Leamington. Its structure confirms the recent conclusions as to the complex nature of the mandibular ramus of Labyrinthodonts, and helps to connect these early amphibians with the Palæozoic Crossopterygian fishes.

Mr. H. C. Beasley has taken advantage of the great find of footprints at Storeton, in Cheshire, last year to re-describe some of the forms hitherto imperfectly known, and $\mathrm{Mr}$. Lomas gave a detailed account of a large slab recently presented to the Liverpool University. This slab gives a track containing fifteen impressions made by the same individual, and the markings are so perfect that the minutest detail of the skin, claws, and movements of the animal which made them, can be observed. It is suggested that Cheirotherium walked erect, and only used the manus to steady itself when bending down to drink or feed. The rocks containing the footprints have been found to contain, besides quartz, felspars, zircon, tourmaline, anatase, rutile, kyanite, staurolite, chert, and numerous black grains not identified.

Mr. A. R. Horwood also contributed to the report an account of the plants and animal remains found in the Leicestershire Trias, and a bibliography of works referring to the flora and fauna of the Keuper of the district.

Mr. L. J. Wills gave an account of a very rich assemblage of fossils he recently obtained from the Lower Keuper of Bromsgrove, in Worcestershire.

Prof. Seeley, in describing the structure of the mandible of a South African Labyrinthodont, pointed out the great resemblance between the British Triassic fauna and that of the Karroo in South Africa.

A discussion on iron-ore supplies was opened by $\mathrm{Mr}$. Bennett Brough and Prof. Sjögren. Mr. Brough contended that as the production and consumption of iron per head of population is increasing year by year, and the world's production in 1905 attained the enormous total of $56,000,000$ tons, the outlook for the future is disquieting, though not necessarily depressing. The future of the home demand is likely to be affected by the development of the basic open-hearth process of steel making, which enables phosphoric ores to be utilised. The development of magnetic concentration and of the briquetting of pulverulent ores for furnace use will render possible greater utilisation of poorer ores, and the electric furnace will doubtless render it possible to use black sands and other titaniferous iron ores, which cannot be treated profitably in the blast furnace.

Prof. Sjögren took a more hopeful outlook in dealing with the Scandinavian iron ores. These are distributed in " ore-provinces" characterised by special geological structures. While the view that the iron-ore supply is unlimited is not well founded, the professor estimated that the total supply for the different provinces in Scandinavia is 1105 millions of tons of ore, equivalent to $5^{82}$ millions of tons of pig iron. Of these, 60 millions contain a low percentage of phosphorus and are suitable for reduction by the Bessemer process, 545 millions are richer in phosphorus and can be worked by the basic-hearth process, and 500 millions are lean ores only profitable to smelt after magnetic concentration.

Continuing the dicussion, Prof. Lapworth congratulated the association upon the importance of the rommunications. He referred to the great changes in the position of the centre of gravity of the iron industry. Years ago the native forests served for the working of the ores when the Weald was the great centre of output. When coal came to be used, the coalfields berame the great centres, and in later davs the ores of the Lias and Oolites had come to the front, and probably for some time they would be the chief British sources of supply.

Mr. G. W. Lamplugh said that an important aspect of

No. I975, voL. 76] 